\title{
DISTAL RENAL TUBULAR (TYPE 1) ACIDOSIS- A CASE REPORT
}

\author{
Shyamali Datta1, Jasninder Singh ${ }^{2}$
}

${ }^{1}$ Assistant Professor, Department of Paediatrics, Mata Gujri Memorial Medical College, Kishanganj, Bihar.

${ }^{2}$ Postgraduate Student, Department of Paediatrics, Mata Gujri Memorial Medical College, Kishanganj, Bihar.

\begin{tabular}{l}
\hline ABSTRACT \\
BACKGROUND \\
A 7-year-old female child presented with growth failure, features of rickets and history of multiple attacks of paralysis. On \\
examination she was retarded in height and weight, had flaccid paralysis of limbs and features of rickets which was not responding \\
to Vitamin D therapy previously. On investigation she showed metabolic acidosis, hypokalaemia, high urinary pH nephrolithiasis \\
and increased renal cortical echogenicity in ultrasonography. Treatment with alkali and potassium was satisfactory, vitamin D and \\
calcium were also given.
\end{tabular}

\section{KEYWORDS}

Distal Renal Tubular Acidosis, Rickets (Refractory), Hypokalaemic Periodic Paralysis, Growth Failure.

HOW TO CITE THIS ARTICLE: Datta S, Singh J. Distal renal tubular (type 1) acidosis- a case report. J. Evolution Med. Dent. Sci. 2017;6(30):2486-2488, DOI: 10.14260/Jemds/2017/538

\section{BACKGROUND \\ Case Report}

A seven years old female child of non-consanguineous marriage from a distant Bihar village, presented with Growth failure, Bone deformities, Polyuria and episodes of Gastroenteritis with vomiting followed by weakness of limbs. For bony deformities, she was treated with Injectable Vitamin $\mathrm{D}$ at least on three occasions during her lifetime in last three four years (as seen in her treatment records), but with no results.

On examination, she showed retardation of weight and height (weight for age $=22 \mathrm{kgs}$, whereas her body weight was 16.5 kgs i.e. - 1 SD;1,2 Height for age $=119 \mathrm{~cm}$, whereas her height was $100.5 \mathrm{~cm}$ i.e. - 2 SD). Widening of bone ends at elbow, wrist, knee and ankle seen, 3,4 which the mother told to be better after present hospital treatment. Muscle power and tendon jerks are diminished, ${ }^{5}$ sensory system unaffected. No cardiorespiratory problem seen, only tachycardia noted on several occasion (92 - 96/minute), ECG normal, Ear and Eye examination showed no abnormality. No sibling history of similar disease. No H/O exposure to any industrial waste ${ }^{6}$ or any $\mathrm{H} / \mathrm{O}$ of any tumour or prolonged drug therapy. ${ }^{7}$ As she was admitted with Gastroenteritis and Dehydration, she was given IV Ringer Lactate.

On investigation Blood Count was normal, no significant pallor, blood urea $32.1 \mathrm{mg} / \mathrm{dL}$ and creatinine was 0.81 showing good renal function. Liver function tests were normal. X-ray bones showed widening and fraying of epiphysis- suggestive of Rickets (which did not respond to multiple Vitamin D doses at past. ${ }^{3}$ Serum Sodium $132 \mathrm{mEq} / \mathrm{L}$ and Potassium $2.6 \mathrm{mEq} / \mathrm{L}$ were low in more than one instances. Serum Calcium was low normal $(7.5 ; 7.9 \mathrm{mEq} / \mathrm{L})$. Serum Bicarbonate was

Financial or Other, Competing Interest: None.

Submission 14-12-2016, Peer Review 01-04-2017,

Acceptance 07-04-2017, Published 13-04-2017.

Corresponding Author:

Dr. Shyamali Datta,

Ashirbad Apartment, Flat 2A,

Khudiram Sarani,

Cooch Behar - 736101,

West Bengal.

E-mail: data.shyamali@gmail.com

DOI: $10.14260 /$ jemds $/ 2017 / 538$

\section{(c) (i) $\$$}

$12.5 \mathrm{mEq} / \mathrm{L}-$ low. Urine $\mathrm{pH}$ was high at 7.25 with +1 Albumin. Blood paO2 82.6 mmHg and pCo2 $22.8 \mathrm{mmHg}, \mathrm{pH} 7.265$. Ultrasonography showed increased cortical echogenicity of left-sided kidney and $3.8 \mathrm{~mm}$ single stone in left renal midpole. The girl was given oral Sodium Bicarbonate $2 \mathrm{mEq} / \mathrm{kg}$ in three divided doses ${ }^{8}$ and oral Potassium Chloride $2 \mathrm{mEq} / \mathrm{kg}$ daily. Injectable Vitamin D and Calcium orally was also given. Followup after three months showed no further paralytic incidence, no progression of bony lesions, growth also improved as evident from gain in body weight.

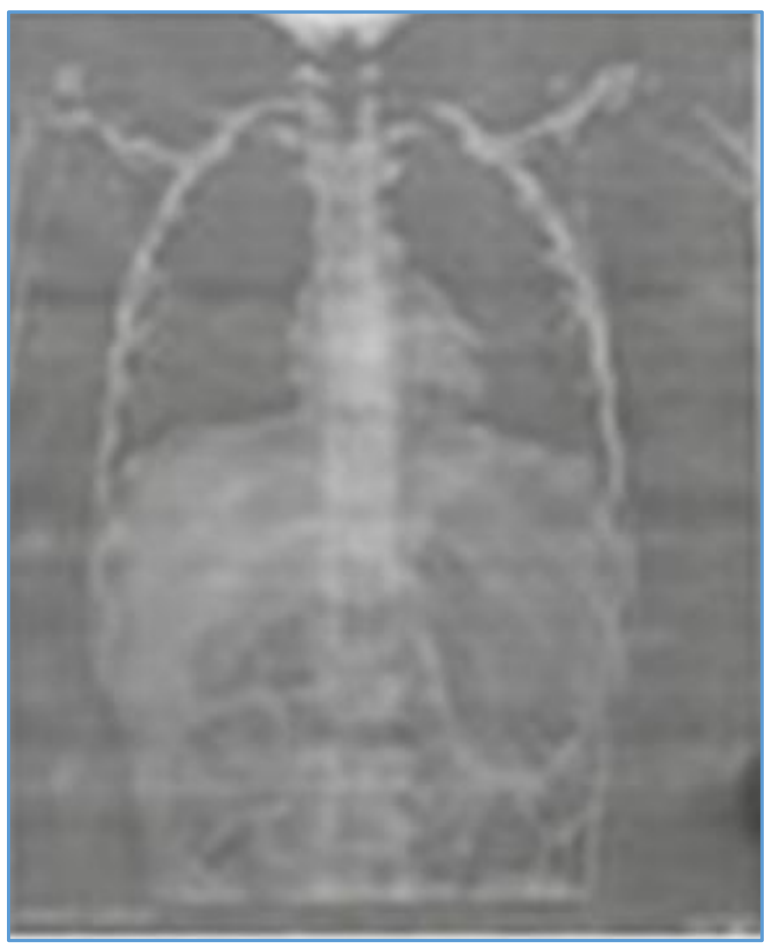



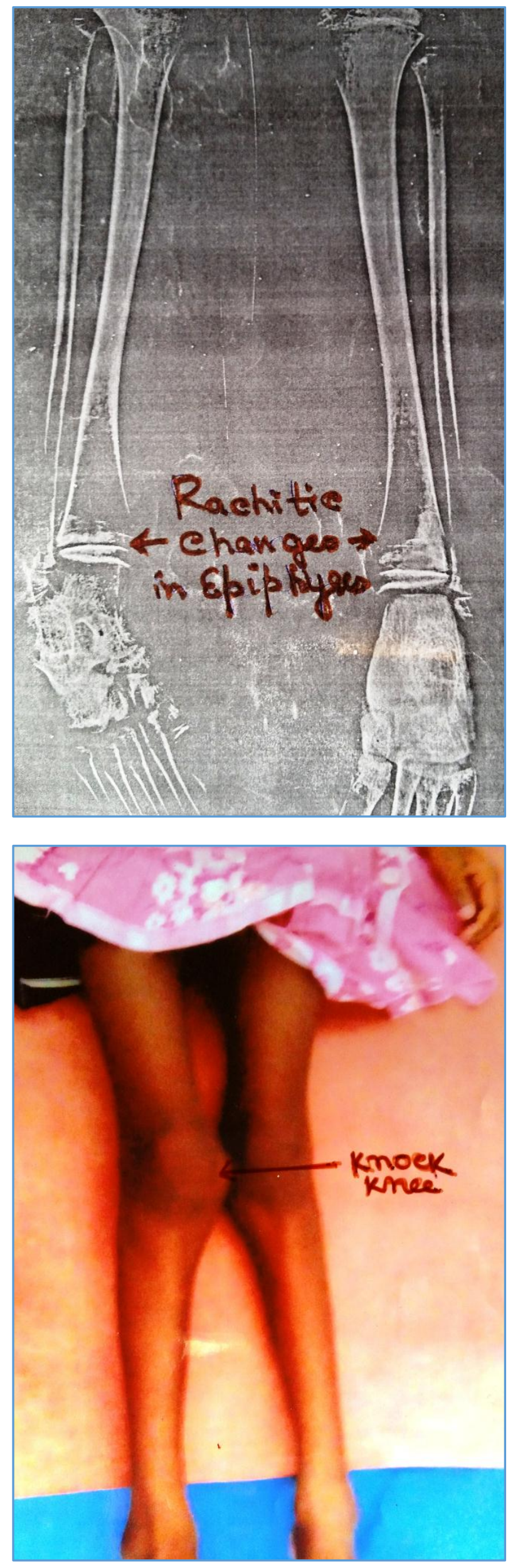

\section{DISCUSSION}

Defective secretion of Hydrogen ion $(\mathrm{H}+)$ in distal renal tubule or reduced proximal renal tubular reabsorption of Bicarbonate (Hco3-) leads to metabolic acidosis. ${ }^{9}$ Urine $\mathrm{pH}$ remains high. Renal function is usually normal. It may be sporadic or secondary to Wilms' Tumour Drugs ifosfamide ${ }^{7}$ Heavy metal Lithium ${ }^{6}$ or Genetic (cystinosis).

Our case was sporadic with Hypokalaemic muscle weakness (seen in Type I variety) due to urinary potassium loss. ${ }^{5}$ Refractory Rickets is due to bone demineralisation ${ }^{3,4}$ in an attempt to buffer acidosis is seen in Type I variety. Renal calculi is also seen in distal renal tubular acidosis (Type I variety). Growth retardation is due to mobilisation of organic materials from bone in an attempt to buffer metabolic acidosis. $^{2}$ Bowing of lower extremities is related to weight bearing at the age of walking. Waddling gait in such children, Genu valgum; Genu varum; short stature is also seen. Radiographic findings include metaphyses widening, fraying and coarse appearing of trabecular bones, Cupping of metaphyses occurs at proximal and distal tibia and at distal femur, radius and ulna bone.

\section{CONCLUSION}

So the case according to our clinical examination, investigation, treatment pattern and response tally very well to be a patient of Distal Renal Tubular Acidosis Type 1 variety.

\section{REFERENCES}

[1] Chang CY, Lin CY. Failure to thrive in children with distal renal tubular acidosis. Acta Paediatr Taiwan 2002;43(6):334-9.

[2] Stickler G. Growth failure in renal diseases. Paedr Clin North Am 1976;23(4):885-94.

[3] Oduwole AO, Giwa OS, Arogundate RA. Relationship between rickets and renal distal tubular acidosis. Ital J Paediatric 2010;36:54.

[4] Brenner RJ, Spring DB, Sebastian A, et al. Incidence of radiographically evident bone disease, nephrocalcinosis, and nephrolithiasis in various types of renal tubular acidosis. NEJM 1982;307(4):217-21.

[5] Wrong OM, Feest TG, Maclver AG. Imune-related potassium losing interstitial nephritis: coparison with distal renal tubular acidosis. QJM 1993;86(8):513-42.

[6] Boton R, Gaviria M, Batlle De. Prevalance pathogenesis and renal dysfunction associated with chronic lithium therapy. Am J Kidney disease 1987;10(5):329-45.

[7] Skinner R, Pearson AD, English MW, et al. Risk factor for Ifosfamide nephrotoxicity in children. Lancet 1996;348(9027):378-80. 


\section{Jemds.com}

[8] Morris RC, Sebastian A. Alkali therapy in renal tubular acidosis: who needs it? J Am Soc Nephrol 2002;13(8):2186-8.

\section{Case Report}

[9] Wrong O, Davies HEF. The excretion of acid in renal disease. QJM 1959;28(110):259-313. 